\title{
How to organise a higher training programme in $\mathrm{A} \& \mathrm{E}$
}

The aim of higher training in $\mathrm{A} \& \mathrm{E}$ is to take doctors who have undergone general professional training and, in five years as a specialist registrar, give them the training and experience necessary to pass the FFAEM examination and take up consultant posts in A\&E. There is a syllabus and a logbook to record the training, produced by the Faculty of Accident and Emergency Medicine, ${ }^{1}$ and regulations for the specialist registrar grade are laid down by the Department of Health. ${ }^{2}$ The Joint Committee on Higher Training in Accident and Emergency Medicine (JCHTA\&E) sets the requirements, but this article gives a personal view of how a programme director might set about designing a training programme. In addition, it is necessary to discuss how an individual hospital, as part of that programme, is approved for training.

\section{Basic structure of a training programme}

A training programme lasts five years. Of these, four should be spent in $A \& E$ and one in other major specialties. The SAC lays down that three months full time working experience is obligatory in general medicine with cardiology, paediatrics, intensive care/anaesthesia, general surgery, and orthopaedics if the trainee has not previously had experience in those specialties. These obligatory attachments must take place in the first half of the programme. Short secondments and day release attachments to other specialties-for example eyes, ENT, and the emergency services-will also need to be arranged throughout the programme, depending on a trainee's previous experience.

There are conflicts in designing a programme. On the one hand, it is clearly useful to have experience in as many different departments and with as many different consultants as possible. On the other hand, it takes time to settle into a new job, find one's feet, and be confident in introducing new ideas. Research takes time to think up and organise (for example, funding, ethics committee approval) and in a short appointment there will be little time to establish it. Audit projects will be of most value educationally if a trainee is in one place long enough to "complete the audit cycle." Longer stays are also useful for management experience. One also needs to consider the trainee's personal and family life. In conurbations it may be possible to design a programme so that a trainee can buy a house from which they can travel to all hospitals on the rotation, but in areas where this is not possible, the scheme should be organised so that there is no more than one house move.

A doctor should gain experience in three or four departments spending not less than one year in each department. It is administratively easier, but not essential, that these departments are within the same postgraduate deanery.

A logical scheme is shown below:

\begin{tabular}{lll}
\hline Year 1 & A\&E & Hospital 1 \\
Year 2 & Obligatory attachments & Hospital 1, 2, or 3 \\
Year 3 & A\&E & Hospital 2 \\
Year 4 & A\&E & Hospital 3 \\
Year 5 & A\&E & Hospital 3 \\
Alternatively, year 5 could be spent in hospital 4 & \\
\hline
\end{tabular}

The programme, though consisting of individual hospital attachments, should be considered as a single scheme with a single person acting as director. The hospitals should, ideally, be close enough for all trainees, wherever they are based, to meet for formal teaching. Consultants in participating hospitals (and others in career grade posts) should be invited to join them for various activities, for example journal clubs, research meetings, etc. Depending on geography, it may be possible to link a programme's educational activities with those of a neighbouring scheme. Hospitals on the scheme may be a logical grouping for interdepartmental audit. Research is important in consultant training but it is likely that the main emphasis on research in the programme will come from just one or two hospitals. A trainee's research may not necessarily be based at the hospital where they are currently working.

There needs to be a plan as to what is to be learnt in each year and in each hospital. The main emphasis in the early part of the scheme should be devoted to gaining clinical skills and experience and in the latter part the emphasis should be on management skills.

For this scheme to run smoothly requires that there are five trainees - one per year. If a scheme has only been allocated four trainees, it may be necessary for one slot at a time to remain empty, but this is far from ideal. Lack of a middle grade doctor for a year will cause problems to the department in providing a service but, more importantly, it will also affect training. A trainee coming to a department where there has been nobody in post for a year will take longer to find his niche than one who steps into the shoes of a colleague. A trainee who moves on with nobody to replace him knows that any projects which he has set up will probably fail.

It is, of course, possible to design other rotations, with trainees going to hospitals 1 and 2 and then any two out of hospitals $3,4,5$, or 6 , but it would be more difficult to ensure that each hospital had a trainee all the time. It may be necessary, from time to time, to add a part time flexible trainee to the system or to allow a trainee to take a year (or more) out, for example for full time research.

Moving to year two of the rotation only occurs on satisfactory completion of the first year. The assessment for this is the responsibility of the regional (or deanery) $A \& E$ higher training committee. There needs to be a set date for all trainees to rotate. If, on completing the rotation, a trainee does not immediately obtain a consultant post, they will move back to hospital 1 in order to allow the rest of the trainees to complete their training.

\section{What hospitals to include}

All hospitals would like a specialist registrar and so there should be no difficulty in finding hospitals wishing to be involved. Although these are training posts rather than service posts, one cannot learn medicine without seeing patients, and hospitals must be busy enough for the trainee to gain adequate experience. In most departments the specialist registrar will see certain categories of patients (for example, the more seriously injured and those who return unexpectedly) and supervise the SHOs. This is also a func- 
tion often taken by staff grade doctors and if a department already has 24 hour cover by staff grade doctors, clinical assistants, etc, there may be little role for a registrar. All doctors in $A \& E$ are expected to be flexible and to give a hand to shift the queue if the department is very busy, but one needs to ensure that a department is not so busy or understaffed that specialist registrars will spend all their time working as an SHO. Multiconsultant departments will usually be better for training than those run by a single handed consultant, as a trainee can observe different ways of working within the same department, will be better supervised, and there is not the risk that they will be used as a quasi second consultant.

It is clearly important that trainees see a range of $A \& E$ departments. I believe that it is essential for all trainees to spend time in a hospital with the tertiary referral specialties of neurosurgery and plastic surgery on site. While these may not be true trauma centres, the ability to handle all that comes through the door without referral onwards gives a special atmosphere to a department. Teaching hospitals, too, have a special atmosphere, with medical student teaching and research going on around, even if the $A \& E$ department itself is not an academic unit. A department with a track record in research and a consultant who could advise and supervise a trainee who wished to do a higher degree would be a valuable addition to a programme. It is also important that trainees see the real world of the DGH. The contrast between inner city, suburban, and largely rural catchment areas is useful to achieve, if possible. A\&E departments also have different facilities (for example, inpatient beds, overnight beds, or no beds) and different styles of working, for example extensive follow up clinics with special interest clinics versus a belief that true emergency physicians should do no follow up work at all. It is useful to experience this variation as long as a department does not deviate from the norm so much as to be considered wrong or dangerous. It is essential that departments meet certain standards in both facilities and backup services on site. There is no point designing a training programme around a hospital that the JCHTA\&E will not accept as suitable for training.

Hospitals occasionally have training recognition removed by the JCHTA\&E. Any obvious problems should have been addressed long before this happens but if a hospital on the scheme does lose recognition, the programme would need altering. The wise programme director would have planned for that eventuality.

Other A\&E departments can be used for short attachments or day release if they can contribute to the training, even if they would not be suitable to have a trainee all the time. These may be specialist (for example, paediatric) departments or departments in which the consultant is acknowledged to have a special expertise (for example, in prehospital care or in relevant information technology). These need not necessarily be within the same deanery. Links with overseas departments and the possibility of organising an exchange with an emergency medicine resident, for example from Australia, will not only make the scheme more attractive to trainees but will enhance their training as they experience a totally different system. Experience abroad in departments which are recognised for training in their own country will usually be accepted as counting towards training, but seek advice from the JCHTA\&E.

\section{Supervision}

Although a trainee will learn from all consultants in a department (and from associate specialists, nurses, etc), one consultant will need to take the responsibility for training and will be the official trainer. Proven ability and willingness to teach will obviously recommend a consultant to be a trainer, as will attendance at courses on teaching, appraisal, etc. It should go without saying that trainers should also have been trained (unless they became a consultant before training was formalised). A trainee will have little faith in a consultant who has not been trained. The trainers will need to meet at intervals and will choose the programme director who will take responsibility for the whole scheme. The trainees' current trainer will act as their educational supervisor for the year but they also need to have somebody to be a mentor for the whole five years. This could be the programme director or another trainer. In addition a trainee needs somebody outside the training programme to turn to if they have got problems that cannot be sorted out locally. This will usually be the chairman of the regional $A \& E$ training committee (or deputy if the chairman is a consultant on the scheme).

All trainees will be formally assessed yearly by the regional $A \& E$ higher training committee. However, informal appraisal by the trainer must also occur regularly so that problems with either training or trainee can be ironed out at the earliest opportunity and so that nothing said at an annual review comes as a shock. The training programme must also be assessed. While more senior trainees are frequently very willing to criticise training or hospital to their trainer, more junior doctors may feel inhibited and so the programme director should also interview the trainees regularly. All supervising consultants should undergo training in assessment and appraisal skills.

\section{Practicalities}

It is important to decide whether to put together a scheme and apply for this to be approved or to construct a training scheme from hospitals which already have JCHTA\&E approval. My preference would be to design a good training scheme with well thought out aims for each year and then to get it approved, and certainly the JCHTA\&E will want to know where a post will rotate to before they approve a hospital for training. The problem is that if one of the three or four departments fails its inspection, the whole scheme falls apart. It is necessary to work with neighbouring schemes. Within the deanery there may be several training departments grouped into two or three higher training programmes. These should work together within the regional training committee so that if one hospital withdraws from a programme, programmes can regroup or other hospitals (of a similar type) within a neighbouring scheme can take trainees until the training programme can be altered. There may also be a need on occasion for trainees to move, and it would be hoped that other schemes within the deanery would cooperate.

There are practical problems both for individual hospitals and for the scheme as a whole. The first is finance. The regional postgraduate dean will usually contribute half of the basic salary (but the current allocation of additional posts comes unfunded) but the trust needs to find the rest. This will involve negotiation with purchasers, who may wish to see improvements or alterations to the $A \& E$ service in return for additional funding. As noted, one year of the training programme needs to be spent outside A\&E. There may be particular problems in funding a year in which it is perceived that there is no benefit to the A\&E department and which cannot be planned in advance to rotate with other specialties, as each trainee's requirements will be different. It must be pointed out to trusts that while there may be little direct benefit to $A \& E$, there will be benefit for the trust as the $A \& E$ trainee helps out with rotas in other specialties and may help in avoiding locum payments in those specialties. The fair solution, though possibly difficult in practice, is 
for the cost of the "year out" to be split between the departments which will benefit from the trainees presence in the other four years.

The final approval of training departments and of training programmes is done by the JCHTA\&E, but they will only inspect a post or scheme if it has been recommended by the regional $A \& E$ higher training committee.

The regional $A \& E$ higher training committee will make recommendations on the distribution of trainees and this should be on educational grounds alone, but they will not recommend a department for training if there is no prospect that the post can be funded. It is necessary to make out a case for the experience and training which you can provide. Write out a prospectus for the committee giving full details of staffing, numbers of patients, teaching, audit, research, recent publications, etc. Provide a timetable for the trainee. You should also be asked to attend the committee to present this. Drawing up this prospectus will not be time wasted as it can also be used for the application to the JCHTA\&E.

Once the regional higher training committee has recommended that you are allocated a specialist registrar, write to the JCHTA\&E asking for an application form and in due course you will be visited by two members of the JCHTA\&E who will wish to inspect the facilities in the department and hospital, to talk to you and to junior staff working in your department, and they may also want to talk to consultants in other acute specialties. Do not expect an instant answer! The visitors draw up a report which will be discussed at the next meeting of the JCHTA\&E. Only then will you receive approval for your post. This will hopefully be for five years but if there are any problems, they may give approval for a shorter time.

Once you have been given approval, you will be given a training number for the post. It is quite possible that a long time has passed since you first tried to get a specialist registrar and you may need to amend the job description that was correct 12 months earlier. You will also need to draw up a person specification. In my own region every job description and timetable has to be approved by the regional specialist training committee before a job is advertised, which adds another few weeks to the delay but at long last the moment arrives when you see the advertisement for your trainee post in the BMJ.

Plymouth

H R GULY

1 Board of the Faculty of Accident and Emergency Medicine. Guidelines for specialist training in accident and emergency medicine. London: Faculty of Accident and Emergency Medicine, 1996.

2 Department of Health. A guide to specialist registrar training. London: $\mathrm{DoH}$, 1996.

\section{Choosing an accident and emergency department computer}

\section{system}

We are all aware of the phenomenal development over the last few years in information technology. Unfortunately its introduction into the NHS has been far from smooth and examples of expensive disasters are well known.

Our specialty more than any other needs the help of computer technology because of the large numbers of patients we process. Accurate information is essential to survive in the present day NHS with its constricting cash limits. Anecdotal evidence is no longer acceptable when making bids for resources.

Unfortunately many of the A\&E systems which have been introduced in the past have had a very limited capability. The recent report from the Audit Commission on improving $A \& E$ services in England and Wales criticised many of the computer systems as being either inflexible or inadequate, producing incomplete data, lack of validation of data, and having poor links between the $A \& E$ computer and other hospital systems.

Seven years ago I was persuaded to "computerise" the A\&E department of this hospital. I had no previous experience of computers either at home or at work and what follows is an account of the lessons learnt on the way!

\section{Type of system}

There are really three choices: (1) a stand alone system; (2) stand alone but interfaced with the hospital PAS (patient administration system); (3) an $A \& E$ module of a hospital information system (HIS).

STAND ALONE SYSTEM

In many ways the stand alone system is the most appropriate for an $A \& E$ department. We work very differently from other departments in the hospital and no two departments work in exactly the same way, so flexibility in the system is essential. An accident department has to be "live" 24 hours a day every day of the year. It can be very annoying if the $\mathrm{A} \& \mathrm{E}$ system goes down every time the hospital system goes down, particularly if this is just for a period of back up.

Stand alone systems are now very reliable and many are capable of carrying out back up procedures while still operating. Unfortunately stand alone systems are not popular with hospital information departments who like to feel they "control" all the systems in the hospital.

STAND ALONE INTERFACED WITH HOSPITAL PAS

Stand alone systems interfaced with hospital PAS systems are probably the compromise solution for most hospitals. They have the advantage of being able to use a single patient number throughout the hospital whichever department the patient presents to. Unfortunately interfacing is expensive and sometimes difficult, and it often depends on goodwill between the various suppliers. The Audit Commission report also pointed out two quite major disadvantages where $A \& E$ computers are linked to hospital systems. In one hospital where the $A \& E$ system was linked to the PAS module it took up to seven minutes to produce an $A \& E$ card at times when other hospital systems were being heavily used. At another hospital computer, "down time" had increased markedly when the A\&E system had been linked to the PAS. A good interface should get round both these problems.

A\&E MODULE OF HOSPITAL INFORMATION SYSTEM

The A\&E modules of hospital HIS systems are often very unsatisfactory. They have often been thrown together with little involvement of $A \& E$ expertise and may have been offered as a "freebie" to the hospital management if they take a particular HIS system for their hospitals.

They are never flexible and any attempt to make changes to them is often met with resistance or incurs great expense. Many $A \& E$ consultants who have been forced to 